\title{
Work engagement and task performance within a global Dutch ICT-consulting firm: The mediating role of innovative work behaviors
}

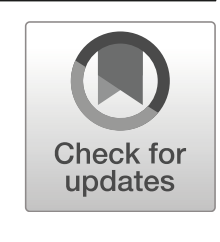

\author{
Llewellyn Ellardus van Zyl ${ }^{1,2}$ (D) $\cdot$ Amber van Oort ${ }^{1} \cdot$ Sonja Rispens ${ }^{1} \cdot$ Chantal Olckers $^{3}$ \\ Published online: 12 July 2019 \\ (C) The Author(s) 2019
}

\begin{abstract}
The information and communication technology (ICT) sector within the Netherlands is a major driver of globalization, the country's economic growth and innovation. The Dutch ICT sector's performance is increasingly becoming dependent upon employee driven innovations in order to address the needs of the sectors they service. In other words, the ICT sector within the Netherlands is largely dependent upon the performance and innovative capacity of its employees; both of which are functions of employee engagement. Given the high demand, and low supply of talent within this sector, ICT organizations need to develop innovative ways to enhance the performance capacities of its people. Developing an engaged and highly innovative workforce seems to be an efficient way to activate employees' performance. As such, the aim of this paper was to investigate the mediating function of employee driven innovative work behaviors in the relationship between work engagement and task performance within the a Dutch ICT consulting firm. A cross-sectional survey-based research design, employing a census-based sampling method, was employed to obtain data from a global ICT consulting firm within the Netherlands $(n=232)$. The Utrecht Work Engagement Scale, the Innovative Work Behavior Scale and the Task Performance Scale was used to assess the associative subjective experiences of ICT employees. The results showed that work engagement is a significant driver for innovative work behaviors, which in turn affects the task performance of employees. Further, innovative work behaviors are therefore important to translate the engaging energies of employees into performance. This paper discusses the theoretical and practical implications of these findings.
\end{abstract}

Keywords Information technology $\cdot$ Innovative work behavior $\cdot$ Task performance $\cdot$ Work engagement

\section{Introduction}

The pace of change, rapid innovation, extreme job demands and high staff turnover rates within the Dutch ICT sector provides an interesting context to investigate the psychological assets that connect work engagement with performance (Luiijf and Klaver 2019). Given that there is an ever-increasing demand for the products and services which Dutch ICT companies provide, the demand for highly skilled and engaged ICT professionals within the Netherlands has grown in response

Llewellyn Ellardus van Zyl

llewellyn101@gmail.com

1 Department of Human Performance Management, University of Eindhoven, Eindhoven, the Netherlands

2 North-West University (VTC), Optentia Research Focus Area, North-West University, Vanderbijlpark, South Africa

3 Department of Human Resource Management, University of Pretoria, Pretoria, South Africa
(Luiijf and Klaver 2015). However, the global demand for these highly skilled individuals cannot be sufficiently met with the current supply nor can higher-education institutions produce talent at the rates required (Brooks et al. 2018). As such, competition between ICT companies for talented IT professionals, at a global level, has dramatically increased during the past decade (Syrek et al. 2013). This increased demand for talented ICT professionals, coupled with the low supply of available skills and free access to the global job market, has made it easy for Dutch IT professionals to seamlessly transition from one opportunity to another (Luftman and Zadeh 2011; Thunnissen et al. 2018; Van Der Wiel 2001). This increased level of skills mobility has caused a talent crisis within the ICT sector (Diedericks and Rothmann 2014). In fact, research suggests that staff turnover within the ICT sector ranges between $25 \%$ and $35 \%$ on an annual basis (Armstrong et al. 2018; Maleh et al. 2019; Naidoo 2016; Naqvi and Bashir 2015).

Dutch ICT organizations have therefore become aware that the long-term retention of talented IT professionals is 
improbable (Armstrong et al. 2018). Resultantly, organizations' focus are shifting away from implementing long-term talent retention programs and started to adopt short- to medium term strategies to maximize the performance returns- and innovative capacities of its current talent pool (Lloyd and Payne 2016). The shift away from a long-term vision for skills retention and capacity building within the ICT sector, has led to short-term profit driven initiatives which results in increased work-related demands (e.g. high time pressures, unrealistic performance targets, strict deadlines, work overload, rude customers etc.) in the absences or even unavailability of job resources (e.g. supervisor- or peer support, physical resources) (Lloyd and Payne 2016; Scholarios et al. 2008). In fact, Prescott and Bogg (2011) found that three out of five ICT professionals now work a 65 to 80 -h work week in order to meet performance related expectations, with little support from the internal organizational system. These high job demands, and low resources lead to extreme fluctuations in both momentary and long-term work engagement (Mauno et al. 2007), which consequently has a negative impact on ICT professionals' task performance (Diedericks and Rothmann 2014; Janse van Rensburg et al. 2018). This "milking-thecow-till-its-dry" performance strategy does not only have the opposite intended performance effect, but it leads to negative consequences for both the employee and the fiscal performance of the company (Naidoo 2016).

Driving 'objective' performance metrics (such as billable hours, chasing targets etc.) is therefore not sustainable and will eventually lead decreased performance, higher staff turnover and a tarnished employer brand (Armstrong et al. 2018; Maleh et al. 2019; Naidoo 2016; Naqvi and Bashir 2015). So, if the focus should not be on driving outputs (i.e. targets or focusing on billable hours), how would ICT consulting firms enhance the performance of its employees? Research suggests that one way is through enhancing the work engagement of employees (Diedericks and Rothmann 2014; Kahn 1990). When IT professionals feel physically, cognitively and emotionally connected to their work, they tend to work harder and perform better (Mazetti et al. 2018). Therefore, when ICT organizations drive engagement, and not performance, people flourish, and the company performs (Diedericks and Rothmann 2014).

It is, however, imperative to note that work engagement, in itself, is not the only pre-requisite for ensuring the sustainable performance of ICT professionals and -consulting firms. Engagement is merely a "driver" that is necessary for an individual to perform (Halbesleben 2010). Various behavioral conditions and psychological assets connecting work engagement and performance is present in the literature (e.g. proactive behaviors, commitment, citizenship behaviors etc), however these are usually context specific (Milfont and Klein 2018). Where one asset might mediate or moderate the relationship within the ICT sector, the same might not be applicable within another context (Chan 1998; Fischer and Poortinga
2018; Milfont and Klein 2018). The nature of the industry is therefore an imperative factor to consider when determining which factor would be necessary to translate work engagement into performance.

One such factor, which could be imperative for the longterm fiscal and performance sustainability of Dutch ICT sector, is the innovative work behaviors (IWB) its employees exert (Cano and Cano 2006). Given that employees within the ICT sector need to be at the forefront of their respective disciplines, being innovative is the only way in which to maintain a competitive edge in the market (Lehner 2018). Within the highly volatile, extremely dynamic, competitive, and rapidly changing nature of the ICT environment (Milfont and Klein 2018; Smith and Haslam 2017), highly engaged ICT professionals may undertake intentional efforts to generate, develop, implement and apply new ideas, processes, products or procedures to enhance organizational efficiency, functioning, effectiveness and competitiveness (De Spiegelaere et al. 2014) which could improve their task related performance (Koopmans et al. 2011). Engaged employees may actively seek out ways in which to improve systems, manage costs, or develop new services/products in attempts to optimize workflow and to create new business opportunities for the company (Newton et al. 2008). IWB of employees is therefore a crucial success factor for the Dutch ICT sector, as it is geared towards the rapid generation of new technological innovations and ideas.

However, given the strategic importance of employee driven innovation within the Dutch ICT sector, it's surprising that academic research into the causes and consequences of such is relatively non-existent. It is important to understand how IWB is triggered by engagement, and how it may relate to the task related performance of ICT professionals within this sector. Understanding the nature, role and function of IWB within the ICT sector, may provide insights into how ICT consulting forms can drive performance in a way that is beneficial for all stakeholders. Therefore, the purpose of this study is to investigate the mediating function of IWB between work engagement and task performance within a global ICT consulting firm, based in the Netherlands. In doing so, we view IWB as a driver for task performance, and IWB as a function of work engagement. Understanding this relationship, could provide valuable information for Dutch ICT organizations to support their talent retention and development strategies.

\section{Literature Review}

\section{Work Engagement and Task Performance}

It's relatively clear through three decades of research, that positive relationships exist between work engagement and numerous conceptualizations of both subjective- and 
objective task performance metrics (c.f. Bakker et al. 2012; Saks and Gruman 2014; Shuck 2011). Work engagement, which refers to "a positive, fulfilling, work-related state of mind that is characterized by vigor, dedication, and absorption" (Schaufeli et al. 2002, p. 74), connects individuals emotionally, cognitively and psychologically to their tasks (Bakker et al. 2012) and work (Mazetti et al. 2018). When individuals are engrossed in their work, they work harder, perform better and complete their work-related tasks faster (Mazetti et al. 2018).

According to Schaufeli et al. (2002, p. 74) three conditions need to be met in order to reap the performance related benefits of work engagement. First, individuals need to show a willingness to invest in and exert high levels of effort into their work and show enduring effort in achieving work related goals even when facing challenges (Vigor). Second, employees need to feel a deep connection to their work, which is characterized by feelings of significance, enthusiasm, inspiration and pride (Dedication). Finally, employees need to feel happily engrossed in and find it difficult to detach from their work, which stems from experiences where time stands still or passes quickly (Absorption) (Agarwal et al. 2012; Schaufeli et al. 2002). Once these conditions or experiences are present, individuals can fully apply their unique skills, capabilities and competences to execute fundamental or substantive workrelated tasks (Campbell 1990).

Specifically, these three work-related engagement conditions result in enhanced task performance. Task performance relates to the efficiency (i.e. speed vs accuracy) in which individual employees are able to complete work-related tasks (Koopmans 2014). It implies behavior that is goal-oriented and that can be scaled or objectively/subjectively measured (Sonnentag et al. 2010). As these behaviours only encompasses tasks that are prescribed- and formally recognized by the organization as outcomes of the job (Bakker et al. 2012) it is often assessed in line with performance rewards systems. Activities that constitute task performance are therefore job specific and will consequently differ between various workrelated functions. Furthermore, what may constitute task performance behavior in one ICT related project/job may not be viewed as such in another (Taris and Schaufeli 2014), however if present it could lead to increased productivity and overall organizational performance (Sonnentag et al. 2010).

In effect, this means that a higher level of work engagement of employees enables companies to obtain or sustain a competitive advantage, because it fuels the task related performance behaviors of their staff (Halbesleben 2010). Because engaged employees tend to be highly connected with their work and the goals of the organization, Christian et al. (2011) found that these employees want to not only meet but exceed the task-related goals that was set out for them. Several recent studies have confirmed that engaged employees not only perform well but are willing to go beyond the extra mile for the company (Bakker and Bal 2010; Bakker et al. 2012; Demerouti and Cropanzano 2010).

Although the relationship between work engagement and task performance is well established outside of the ICT sector, the mechanisms connects such is still unclear (Schaufeli 2018). Research has shown that assets connecting work engagement and performance differs between contexts and populations (Halbesleben 2010; Shuck 2011). Specifically, the same asset which mediates or moderates a relationship in one context may not do so in another (Chan 1998; Fischer and Poortinga 2018; Milfont and Klein 2018). This phenomenon is clearly visible in contexts that are known to be highly volatile, extremely dynamic, exceedingly competitive, and subjected to continuous, rapid change (Milfont and Klein 2018; Smith and Haslam 2017), such as the ICT sector. One asset, which is of particular relevance to the ICT sector which could connect engagement and task performance is Innovative Work Behaviors of employees.

\section{Mediating Role of Innovative Work Behavior}

Organizations within the ICT sector are increasingly faced with the need to maximize the innovative potential of employees to sustain or obtain a competitive advantage (Hanif and Bukhari 2015). IWBs are therefore expected to be vital within the ICT sector as it directly impacts organizational performance (Kim and Park 2017; Shanker et al. 2017). From this perspective, IWB is defined as the efforts and behaviors exerted by employees which are directed at the introduction, generation and/or application of ideas, products, procedures, or processes which aim to benefit the relevant unit of adoption significantly and are new to that unit (West and Farr 1989). Its comprised out of (a) idea generation, (b) idea promotion, and (c) idea realization (Janssen 2000). Idea generation is the phase where employees identify problems and generate new and useful ideas to address problems in any domain (Janssen 2000; De Spiegelaere et al. 2014). In the idea promotion phase, support and recognition from potential allies (friends, colleagues, and sponsors) is sought through promotion of generated ideas (Hanif and Bukhari 2015). Finally, the idea realization phase refers to the phase where newly developed ideas are prototyped and implemented within a work role, a group or the total organization (Janssen 2000). It is important to note that IWB is 'discretionary behavior' and thus not included in the prescribed roles of the employee (Shanker et al. 2017).

The innovation process should therefore be viewed as a discontinuous process where individuals can be involved in any combination of the behavioral tasks at any time (De Spiegelaere et al. 2014). These types of behaviors are purely extra-role behaviors which are a result of the intrinsic motivation of the employees (Ramamoorthy et al. 2005). When an employee engages in these IWBs, one can improve their job 
by generating new ideas and improvements of processes (Ramamoorthy et al. 2005). This will enable them to do their jobs better and leads to enhanced task performance (Aryee et al. 2012).

Employees will be more likely to engage in IWB when they expect that displaying such behavior will benefit their work. When an employee engages in IWB, it enables them to do their jobs better which leads to enhanced task performance (Aryee et al. 2012). Aryee et al. (2012), Gong et al. (2009), as well as Yuan and Woodman (2010) confirmed a positive relation between IWB and performance.

As an outcome of engagement, Agarwal (2014) as well as Kim, Park and Lee (2014) showed that engaged employees put significant effort into IWB for their organizations. According to Anwar and Niode (2017), employees that experience high levels of engagement, tend to proactively solve problems and are encouraged to find new information and ideas and apply them to work. Similarly, Sonnentag (2003) reported that employees with high work engagement also tend to encourage others in taking initiative in their work. Work engagement is therefore suggested to be positively related to IWB thereby enabling employees to efficiently deal with the pressures and challenges that come along with the changing business environment (Kataria et al. 2014). When employees are fully engrossed in their work, they have the psychological capacity to successfully activate IWB. ICT-professionals are then able to create innovative means to improve their work, to find simpler and faster means to complete tasks, and to look for new business opportunities which all results in higher reports of task performance (Aryee et al. 2012). This study therefore supposes that IWB has a mediating effect on the relationship between work engagement and task performance within a global ICT company.

$\mathrm{H}_{1}$ : Work engagement has an indirect effect on task performance by means of innovative work behaviors

\section{Method}

\section{Research Design}

A quantitative cross-sectional online survey-based research design was used to investigate the relationships among the variables.

\section{Research Setting}

This research is conducted at a global ICT company with more than 100,000 employees. The Dutch branches of this company were selected to participate in this study. The company offers digital services (e.g. big data and security, business and platform solutions, digital payments and e-transactions) and infrastructure to a conglomerate of global clients. Employees in the Netherlands mainly work project-based, remotely from the office and within virtual teams.

\section{Participants}

A census sampling strategy was employed to gather the data of a diverse group of employees who are employed by the global IT-company and located in the Netherlands $(N=$ 3350). Census-based sampling attempts to acquire data from an entire population systematically (Gupta and Kabe 2011). Electronic surveys were personally distributed to the entire population, as more than $80 \%$ of staff worked off site or were based at clients' offices. Data were gathered from $232^{1} \mathrm{em}-$ ployees $(n=232)$. Table 1 shows the general biographical characteristics of the respondents. The majority of the participants were Dutch $(95.3 \%)$ men $(93.1 \%)$ between the ages of 51 and 60 years old $(41.0 \%)$ who held full-time employment (78.0\%). The sample mainly consisted of employees working in Eindhoven (41.3\%), at the Business and Platform solutions department $(87.5 \%)$ and held at least a Bachelor's degree $(56.89 \%)$. The sample is roughly in line with the distribution of the actual population, where the male/female ratio is known to be $89 / 11$ (vs $93 / 7$ in our sample) and the predominant age range is between 51 and 60 years $(41 \%$ vs $43.4 \%$ in our sample).

\section{Measuring Instruments}

Four self-report instruments were used to measure study variables.

Biographical details were gathered by use of a selfreporting biographical questionnaire. Demographic information relating for example to the gender, age, nationality, level of education, occupational status and departments of the respondent were requested.

Work engagement Work engagement was measured by the Utrecht Work Engagement Scale with nine items (UWES-9) (Schaufeli and Bakker 2003). The UWES-9 is a self-report measure which includes items for the assessment of the three engagement dimensions named in Schaufeli et al. (2002): vigor, dedication and absorption. Each of these dimensions are measured with three items, together providing the instrument of nine items. Items are rated on a 7-point Likert scale from $0=$ 'never' to $6=$ 'always'. Example items are: "At my work, I feel bursting with energy" (vigor), "My job inspires me" (dedication) and "I am proud of the work that I do" (absorption). High

\footnotetext{
${ }^{1}$ The low response rate was largely influenced by a restructuring process which was taking place in the company at the time
} 
Table 1 Characteristics of participants $(n=232)$

\begin{tabular}{|c|c|c|c|}
\hline Item & Category & Frequency $(f)$ & Percentage $(\%)$ \\
\hline \multirow[t]{2}{*}{ Gender } & Male & 216 & 93.1 \\
\hline & Female & 16 & 6.9 \\
\hline \multirow[t]{6}{*}{ Age (years) } & $21-30$ & 21 & 9.1 \\
\hline & $31-40$ & 26 & 11.2 \\
\hline & $41-50$ & 46 & 19.8 \\
\hline & $51-60$ & 95 & 41.0 \\
\hline & $61+$ & 40 & 17.2 \\
\hline & Missing or prefer not to be identified & 4 & 1.7 \\
\hline \multirow[t]{3}{*}{ Nationality } & Dutch & 221 & 95.3 \\
\hline & Other & 7 & 3.0 \\
\hline & Missing or prefer not to be identified & 4 & 1.7 \\
\hline \multirow[t]{5}{*}{ Educational level } & High School & 37 & 16.0 \\
\hline & Intermediate vocational education & 3 & 1.3 \\
\hline & Bachelor's Degree & 123 & 56.9 \\
\hline & Master's Degree & 57 & 24.6 \\
\hline & Advanced Graduate work or $\mathrm{PhD}$ & 3 & 1.3 \\
\hline \multirow[t]{3}{*}{ Status of Occupation } & Full-time employed & 181 & 78.0 \\
\hline & Part-time employed & 43 & 18.5 \\
\hline & Intern & 8 & 3.4 \\
\hline \multirow[t]{5}{*}{ Department } & Business \& Platform Solutions & 203 & 87.5 \\
\hline & Infrastructure \& Data Management & 17 & 7.3 \\
\hline & Big Data \& Cybersecurity & 8 & 3.4 \\
\hline & Sales & 1 & 0.4 \\
\hline & Support & 3 & 1.3 \\
\hline
\end{tabular}

scores on all three dimensions indicate a high level of work engagement (Agarwal et al. 2012). Within this sample, the overall scale (Cronbach's $\alpha$ : 0.98) as well as its sub-dimensions (Vigor: $\alpha=0.89$; Dedication: $\alpha=0.92$; Absorption: $\alpha=0.89$ ) showed high levels of internal consistency.

Innovative Work Behavior Innovative Work Behavior was measured using the nine items scale from Janssen (2000). This instrument measures the tree components of IWB: idea generation, idea promotion and idea realization. Each of these dimensions consists of three items, together providing the instrument of nine items. Respondents had to indicate the frequency in which they perform innovative activities on a 5-point Likert scale ranging from $1=$ 'never' to $5=$ 'always'. Example items are: "Creating new ideas for difficult issues" (idea generation), "Mobilizing support for innovative ideas" (idea promotion) and "Transforming innovative ideas into useful applications" (idea realization). The three dimensions of IWB are combined in such a way that a higher sum of the scores indicates a higher level of IWB (Agarwal et al. 2012). Within the current study, the Cronbach Alpha's of the entire scale $(\alpha: 0.94)$ and its subdimensions (Idea generation: $\alpha=0.93$; Idea Promotion: $\alpha=0.88$; Idea Realization: $\alpha=0.84$ ) showed to be at acceptable levels. Task performance Task performance was measured using the Task Performance sub-scale of the Individual Work-Performance Questionnaire developed by Koopmans (2014). This sub-scale consists of seven items and is rated on a 7-point Likert scale ranging from $1=$ 'never' to $6=$ 'always'. Example items are: 'I managed to plan my work so that it was done on time" and "My planning was optima". Respondents had to fill in how they were able to perform each of the items within a recall period of 3 months. The Cronbach Alpha for this scale, in this study was 0.88 .

\section{Statistical Analysis}

Data was processed with SPSS 25 (IBM 2017) and MPlus v. 8.1 (Muthén and Muthén 2018). First, data normality was estimated through the computation of descriptive statistics (means, standard deviations, skewness, kurtosis) and relationships determined through Pearson correlation coefficients $(p \leq 0.01)$. Further, to determine the presence of common 
method bias both Harman's (1976) single factor test, and a series of common latent factor methods was employed (Podsakoff et al. 2003; Tehseen et al. 2017).

Second, a competing measurement model strategy through structural equation modelling (SEM) with the maximum likelihood estimator (ML) was employed to assess the model fit for both the competing measurement models and final structural model (Muthén and Muthén 2018). Based on the recommendations of Wang and Wang (2012), model fit was determined through: (1) absolute fit indices (Chi-square, Root Mean Square Error of Approximation (RMSEA: < 0.08) and the Standardized Root Mean Residual (SRMR: < 0.08), (2) incremental fit indices (Tucker-Lewis index (TLI: $>0.90$ ) and the Comparative Fit Index (CFI: $>0.90)$ and (3) comparative fit indices (Akaike Information Criterion (AIC) and Bayesian Information Criterion (BIC). A structural model was estimated based on the best-fitting measurement model. The former with the relationships amongst the latent constructs as represented by observed variables, whereas the latter with only the logical linear relationship between latent constructs. Items could correlate freely, and no extra constraints were placed on the model.

Third, the indirect effects of IWB on the relationship between work engagement and task performance were assessed through a path model with the bias-corrected bootstrapping (BCB) method proposed by Preacher et al. (2010). A 50000 $\mathrm{BCB}$ was set to impute preferable confidence limits and standard errors for the indirect effect assessment at the $95 \%$ confidence interval limit.

\section{Results}

To determine the mediating role of IWB on the relationship between work engagement and task performance, a four phased approach was employed. First, the general descriptive statistics and correlations are presented. Second, the competing measurement models discussed. Third, the results from the structural model are tabulated and presented. Finally, the indirect effect assessment of IWB on the relation between work engagement and task performance is evaluated.

\section{Descriptive Statistics, Reliabilities, Correlations and Test for Common Method Bias}

To test for common method bias (CMB), a series of statistical approaches were taken. First, Harman's single factor test was performed where all the observed indicators are entered into an unrotated exploratory factor analysis. No single factor could be extracted, and common shared variance was below the suggested $35 \%$. Second, a confirmatory factor analytical approach using a single factor indicator (with all of the observed variables loading directly onto such) was used to further explore CMB (Tehseen et al. 2017). This test also failed to produce a single factor which implies CMB may be absent. Finally, Podsakoff et al. (2003) suggested the use of a common latent factor approach to detect CMB. Here a single unmeasured common latent factor is constructed with regression lines leading to each observed variable in a measurement model. These paths are constrained to be equal, and the variance of the common factor constrained to 1 . The results showed that the variance explained by the common latent factor is low and the correlational paths between variables are similar to the model without the common factor. Therefore, common method bias is not a concern in this study.

The descriptive statistics, scale reliabilities and Pearson correlations are shown in Table 2. The results showed that all variables were normally distributed, with Skewness and Kurtosis being smaller than the suggested range of -2 and 2 . Further, Pearson correlation estimation showed that statistically significant positive relationships between all variables were found $(p<0.01)$.

\section{Comparing Competing Measurement Models}

A competing measurement modelling strategy employing a confirmatory factor analytical approach was used to determine the best fitting model for the current data. In this approach, observed variables were treated as indicators for first order latent variables. No items or error terms were correlated or removed to improve model-fit.

Five measurement models were computed and systematically compared:

- Model 1. A one factor model for all three variables were fitted to the data. Work engagement and IWB consisted of nine items each and task performance consisted of seven items.

- Model 2. A three-factor model for work engagement was fitted to the data where three items loaded on each of the following: vigor, dedication and absorption. A one-factor model for both IWB and task performance was fitted. Nine items loaded directly on IWB and task performance was comprised of all seven items.

- Model 3. A second order factorial model for work engagement was created which comprised out of three first order factors (vigor, dedication and absorption). Similarly, a second order factorial model for IWB was created which comprised out of three first-order factors: idea generation, idea promotion and idea realization. Finally, task performance was estimated as a one factor model comprised of all seven items.

- Model 4. A one-factor model for work engagement and task performance was fitted to the data, where all items loaded directly on the latent constructs. IWB was estimated as a second order factor, comprised out of three first 
Table 2 Descriptive statistics, and Pearson Correlations $(n=232)$

\begin{tabular}{|c|c|c|c|c|c|c|c|c|c|c|c|c|}
\hline Construct & $\mu$ & $\sigma$ & $S K$ & $R k u$ & 1 & 2 & 3 & 4 & 5 & 6 & 7 & 8 \\
\hline 1. Work Engagement & 5.02 & 1.14 & -0.80 & 0.99 & - & - & - & - & - & - & - & - \\
\hline 2. Vigor & 4.96 & 1.22 & -0.70 & 0.56 & 0.93 & - & - & - & - & - & - & - \\
\hline 3. Dedication & 5.17 & 1.20 & -0.80 & 0.78 & 0.96 & 0.88 & - & - & - & - & - & - \\
\hline 4. Absorption & 4.92 & 1.24 & -0.70 & 0.57 & 0.90 & 0.72 & 0.80 & - & - & - & - & - \\
\hline 5. $I W B$ & 2.35 & 0.89 & 0.68 & 0.16 & 0.30 & 0.30 & 0.28 & 0.26 & - & - & - & - \\
\hline 6. Idea Generation & 2.85 & 0.99 & 0.16 & -0.59 & 0.25 & 0.24 & 0.27 & 0.21 & 0.86 & - & - & - \\
\hline 7. Idea Promotion & 2.08 & 0.98 & 0.98 & 0.43 & 0.30 & 0.30 & 0.28 & 0.24 & 0.90 & 0.63 & - & - \\
\hline 8. Idea Realization & 2.11 & 0.97 & 0.88 & 0.02 & 0.27 & 0.26 & 0.25 & 0.23 & 0.92 & 0.69 & 0.79 & - \\
\hline 9. Task Performance & 3.65 & 0.70 & -0.61 & 0.88 & 0.42 & 0.41 & 0.40 & 0.35 & 0.30 & 0.30 & 0.31 & 0.30 \\
\hline
\end{tabular}

$\mu$ mean, $\sigma$ standard deviation, $S K$ skewness, $R k u$ kurtosis, $I W B$ innovative work behavior. All values of correlations are statistically significant at $\mathrm{p}<0.01$

order factors (idea generation, idea promotion and idea realization).

- Model 5. A three-factor model for work engagement was fitted to the data where three items loaded on each of the following: vigor, dedication and absorption. A three-factor IWB was estimated which comprised out of idea generation (3 items), idea promotion (3 items) and idea realization ( 3 items). Finally, task performance was estimated as a one factor model comprised of all seven items.

Table 3 provides an overview of the values of the fit indices as suggested in Table 2 for all four competing measurement models.

Table 3 indicates that the original theoretical model (Model 3 ), which comprised of two second order factorial model for both work engagement (vigor, dedication, absorption) and IWB (idea generation, idea promotion, idea realization) as well as a one-factor model for task performance fitted the data significantly better than the other models $\left(\chi_{(266, N=232)}^{2}=\right.$ 542.23; $\mathrm{CFI}=0.94 ; \mathrm{TLI}=0.93 ; \mathrm{RMSEA}=0.06 ; \mathrm{SRMR}=$ 0.05). Further, Model 3 showed better comparative fit on both the AIC and BIC values as compared to Models 1, 2, 4 and 5. However, Model 4 showed acceptable fit on all fit indices, but still comparatively lower than Model $3\left(\Delta \chi^{2}=47.97 ; \Delta d f=3\right.$; $\Delta \mathrm{CFI}=0.01 ; \Delta \mathrm{TLI}=0.01 ; \Delta \mathrm{RMSEA}=0.01)$. Therefore, only Model 3 was be retained for conversion to the structural model.

\section{Developing the Structural Model}

A structural path model was estimated based for the best fitting measurement model (Model 3), as it showed to be the most parsimonious and it most accurately represented the data. The structural model for Model 3 (c.f. Figure 1: $\chi^{2}{ }_{(266, N=}$ $232)=573.93, p<0.001 ;$ TLI $=0.93 ;$ CFI $=0.94 ;$ RMSEA $=$ 0.06 ; SRMR $=0.05$ ) showed acceptable fit.

Work engagement statistically significantly predicted $14 \%$ of the total variance in IWB $(\beta: 0.32$; S.E: $0.07 ; p<0.01)$.
Similarly, IWB statistically significantly predicted $18 \%$ of the variance in Task performance $(\beta: 0.29$; S.E: $0.07 ; p<$ 0.01). In the presence of IWB, Work Engagement did not statistically significantly predict Task performance $(\beta: 0.10$; S.E: $0.06 ; p>0.01)$.

\section{Assessing the Indirect Effect of IWB}

Based on the structural model, the procedure proposed by Preacher et al. (2010) was employed to assess whether IWB mediates the relationship between work engagement and task performance. To construct two-sided bias-corrected confidence intervals (CI) at the $95 \%$ marker, the bias-corrected bootstrapping method with 50,000 iterations was computed.

The results showed that a statistically significant indirect effect exists between work engagement, IWB and task performance at the $95 \% \mathrm{CI}$ (lower $=0.01$ to upper $=0.09$ ). As the CIs between work engagement and task performance through IWB does not include zero, IWB indirectly effect the aforementioned relationship. Therefore, Hypothesis 1 was accepted.

\section{Discussion}

The purpose of this paper was to investigate the mediating function of IWB on the relationship between work engagement and task performance among employees in a global ICTcompany. The context of the ICT sector was deliberately chosen because of its high pace of change, rapid innovations, extreme job demands and high staff turnover rates (Janse van Rensburg et al. 2018). The results revealed that work engagement was positively related to innovative work behavior, indicating that the more engaged employees are, the more innovative behavior they demonstrate. Furthermore, we also found innovative work behavior to be positively related to task performance. In addition, the results demonstrate that work 
Table 3 Fit of measurement models

\begin{tabular}{lllllllll}
\hline Model & $x^{2}$ & $d f$ & RMSEA & SRMR & CFI & TLI & AIC & BIC \\
\hline Model 1 & 827.28 & 272 & 0.09 & 0.05 & 0.88 & 0.87 & $13,427.39$ & $13,693.85$ \\
Model 2 & 780.42 & 269 & 0.09 & 0.05 & 0.89 & 0.87 & $13,385.40$ & $13,662.10$ \\
Model 3 & 542.23 & 266 & 0.06 & 0.05 & 0.94 & 0.93 & $13,153.21$ & $13,440.17$ \\
Model 4 & 590.20 & 269 & 0.07 & 0.05 & 0.93 & 0.92 & $13,195.18$ & $13,471.88$ \\
Model 5 & 910.11 & 268 & 0.10 & 0.05 & 0.86 & 0.85 & $13,517.09$ & $13,797.21$ \\
\hline
\end{tabular}

engagement indirectly affected task performance, via innovative work behavior.

Our finding that work engagement is positively related to innovative work behavior further corroborates previous findings (e.g. Aryee et al. 2012). This is an important finding because employees' innovative behaviors are indicative of the overall level of innovativeness of a company (DiLiello and Houghton 2006). Engaged employees are characterized by high levels of energy, enthusiasm, focus, inspiration, intensity, mental resilience, and persistence, which facilitate their innovative work behaviors. Perhaps engaged employees can "save" or "refuel" resources by performing their tasks in an efficient manner, enabling them to pursue discretionary activities. On the other hand, engaged employees may have a broad definition of what their tasks are, and because of that engage in innovative work behaviors (Christian et al. 2011). In the context of this ICT company, we suspect that engaged employees may implement innovative ideas in order to deal with demands such as the rapidly changing work environment (Chang et al. 2013). The fact that the strength of this relationship between work engagement and IWB is weaker than found in previous studies (Aryee et al. 2012; Shanker et al. 2017), may be due to the remote and virtual working environment of the organization.

The results of this study further established a positive relationship between IWB and task performance. When engaging in innovative work behaviors, employees gather and process a lot of information which enables them to learn. Further, when promoting and implementing ideas employees are likely to encounter opposition and critique from colleagues. These experiences help them to find new ways to solve problems, which enhances their task performance (Aryee et al. 2012; Newton et al. 2008). Of course, it may also be that employees engage in IWB only when they believe that doing so will help their task performance.

Finally, the study showed support for the mediating role that IWB could play in relation to world engagement and task performance within this ICT contexts. When employees these employees are more engaged, they may be more inclined to think up, promote and implement innovative ideas in order to enhance their task performance. IWB can therefore be considered as bridging mechanism which connects the engagement of employees with their task performance.
These findings are in line with research of Aryee et al. (2012) who found evidence of this effect within a context outside of the ICT-sector.

Overall, the results of this study were similar to findings done on employees in general or employees from another type of organization, and gives us confidence in the generalizability of our findings.

\section{Implications}

For the research literature, this study indicates that work engagement (indirectly) and IWB (directly) are drivers of task performance within this global IT-company. From a theoretical viewpoint, the fact that IWB acts as an antecedent for task performance as well as an outcome of work engagement is an important contribution.

The ecological organizational volatility, constant change and high job demands which ICT-professionals are exposed to, may be important factors which likely influence the level of work engagement (Aryee et al. 2012). This ICT organization could explore active means through which to enhance work engagement in order to aid employees to be more innovative and to perform better. We know from past research that increasing resources fuels work engagement, which can be accomplished, for example, via job crafting (Dubbelt et al. 2019). Job crafting is a bottom-up work design strategy in which employees shape their own work environment such that it fits their individual needs by adjusting the prevailing job demands and resources (Tims and Bakker 2010). ICT organizations can create the conditions to facilitate job crafting behaviors, for example, by offering job crafting training (see Dubbelt et al., 2019). Furthermore, supervisors could actively engage in providing necessary feedback, or to become coaches to employees, such that employees are supported and become motivated to develop and grow in their jobs (Anwar and Niode 2017; Demerouti 2014).

\section{Limitations and Future Research}

This study has some limitations which need to be acknowledged. The first limitation is the cross-sectional nature of the research design. Although cross-sectional studies have some merit (Spector 2019), the design prevents us from making 


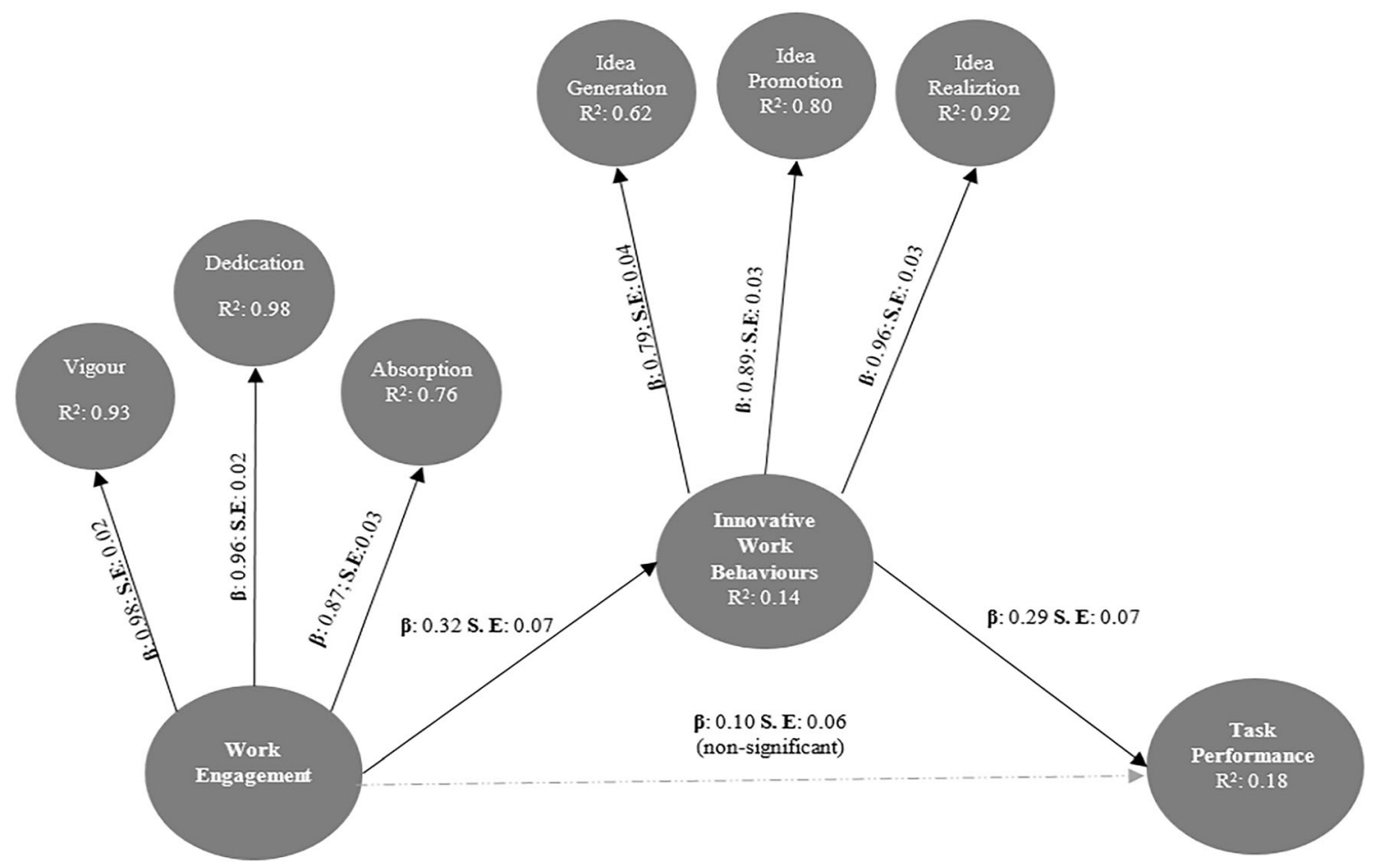

Fig. 1 Structural Model - Model 3

statements about the causal order of the constructs in our model. We based our assumptions about the model on previous studies, but we do acknowledge that future research with a longitudinal design is needed to see whether the current model holds or whether an alternative model provides a better fit.

A second limitation of this research is the self-report, and single levelled nature of the assessment. Self-report measures are known to be volatile and sensitive to momentary changes in the environment. Further research should attempt to utilize more objective measures of both performance and innovative work behavior (e.g. manager ratings; objective organizational performance).

A third limitation rests on the size and distribution of the sample. Although the sample is representative for the population in terms of age and gender, it does not provide enough variation in demographic variables to fully explore reasons for the results. It is (for example) improbable to compute measurement invariance, multi-group analysis or even MANOVAs. As such, the possibilities of exploring the contextual, and demographic attributors is limited. A larger sample would have allowed more powerful analysis. Future research could involve sending a direct mail to all employees to increase the number of respondents. Finally, it would be important to determine, measure and assess other possible mediating mechanisms which could indirectly affect work engagement and task performance.

Further, the results showed that IWB could indirectly affect the relationship between work engagement and task performance, although the reported effect was small. This indicates that other (unobserved) mediating mechanisms may also play a substantial role in explaining relationship. In order to fully understand how engagement could be translated into performance, future research should be aimed at identifying alternative forms of extra-role behaviors which could act as mediators within this context. Given the dynamic nature of the ICT environment, three extra-role behaviors could play a significant role in this regard: employee pro-activity (Salanova and Schaufeli 2008), organizational citizenship behaviors (Kim and Park 2017) and pro-social behaviors (Harari et al. 2016). Salanova and Schaufeli (2008) argued that for engagement to translate into both innovation and performance, employees need to exert proactive behaviors. Engaged employees are likely to proactively contribute to the achievement of organizational goals because they feel emotionally, psychologically, cognitively and physically responsible for such (Shuck 2019). When employees feel attached to or responsible for the organization's goals, they are more likely to generate innovative solutions to complex problems and resultantly, perform better (Kim and Park 2017). Further, when individuals feel engaged at work, various organizational citizenshipand pro-social behaviors are activated (Harari et al. 2016). Engaged employees often act altruistically, courteously, and activate virtuous civic behaviors at work (Rich et al. 2010, 2010). In effect, they go beyond the call of duty to aid others, and the organization in the achievement of work-related goals. These factors should be further explored within the current 
ICT context as possible means to explain how engagement translates into performance.

Finally, it might also be interesting to investigate the antecedents of work engagement in future research in ICTcompanies to reveal possible ways for management to improve performance. By use of the job demands- resources model, it is possible to reveal which resources have the strongest impact on work engagement in this company (Bakker and Demerouti 2008). For example, job autonomy and social support could have a positive impact on work engagement of employees (Bakker and Demerouti 2008).

\section{Conclusion}

This study provides one of the first empirical inquiries into the indirect effects of IWB in the well-established relationship between work engagement and task performance. In terms of practical implications, the findings indicate that organizations can gain an increase in performance when they encourage their engaged employees to engage in IWB. Should employees experience work engagement, it may activate the innovative work-related behaviors of employees which in turn could yield positive returns on their task performance will follow.

Acknowledgements The authors would like to extend their gratitude to the two independent reviewers who aided in enhancing the quality of this manuscript. Further, we would also like to extend our gratitude to Martin Hundepool for his continued commitment and support in the realization of our projects.

\section{Compliance with Ethical Standards}

Conflict of Interest The authors declare that they have no conflict of interest and that the APA guidelines on Ethical Research practices were strictly adhered to.

Open Access This article is distributed under the terms of the Creative Commons Attribution 4.0 International License (http:// creativecommons.org/licenses/by/4.0/), which permits unrestricted use, distribution, and reproduction in any medium, provided you give appropriate credit to the original author(s) and the source, provide a link to the Creative Commons license, and indicate if changes were made.

\section{References}

Agarwal, U. A. (2014). Linking justice, trust and innovative work behaviour to work engagement. Personnel Review, 43(1), 41-73. https:// doi.org/10.1108/PR-02-2012-0019.

Agarwal, U. A., Datta, S., Blake-Beard, S., \& Bhargava, S. (2012). Linking LMX, innovative work behaviour and turnover intentions. Career Development International, 17(3), 208-230. https://doi.org/ $10.1108 / 13620431211241063$.
Anwar, R. \&, Niode, S. H. M. (2017). The effects of learning organization towards employees' innovative behavior mediated by work engagement (a study in Indonesia). International Conference of Organizational Innovation. Advances in Intelligent Systems Research, Vol. 131, 159-164.

Armstrong, D., Riemenschneider, C., Buche, M. W., \& Armstrong, K. R. (2018). Mitigating turnover intentions: Are all IT workers warriors? AIS Transactions on Replication Research, 4(1), 10.

Aryee, S., Walumbwa, F. O., Zhou, Q., \& Hartnell, C. A. (2012). Transformational leadership, innovative behavior, and task performance: Test of mediation and moderation processes. Human Performance, 25(1), 1-25. https://doi.org/10.1080/08959285.2011. 631648.

Bakker, A. B., \& Bal, P. M. (2010). Weekly work engagement and performance: A study among starting teachers. Journal of Occupational and Organizational Psychology, 83, 189-206. https://doi.org/10.1348/096317909X402596.

Bakker, A. B., \& Demerouti, E. (2008). Towards a model of work engagement. Career Development International, 13(1), 209-223. https://doi.org/10.1108/13620430810870476.

Bakker, A. B., Demerouti, E., \& Ten Brummelhuis, L. L. (2012). Work engagement, performance, and active learning: The role of conscientiousness. Journal of Vocational Behavior, 80(2), 555-564. https://doi.org/10.1016/j.jvb.2011.08.008.

Brooks, N. G., Greer, T. H., \& Morris, S. A. (2018). Information systems security job advertisement analysis: Skills review and implications for information systems curriculum. Journal of Education for Business, 93(5), 213-221. https://doi.org/10.1080/08832323.2018. 1446893.

Campbell, J. P. (1990). Modeling the performance prediction problem in industrial and organizational psychology. In M. D. Dunette \& L. M. Hough (Eds.), Handbook of industrial and organizational psychology (Vol. 1, 2nd ed., pp. 687-7632). Palo Alto: Consulting Psychologists Press.

Cano, C. P., \& Cano, P. Q. (2006). Human resources management and its impact on innovation performance in companies. International Journal of Technology Management, 35(1-4), 11-28.

Chan, D. (1998). Functional relations among constructs in the same content domain at different levels of analysis: A typology of composition models. Journal of Applied Psychology, 83(2), 234. https://doi. org/10.1037/0021-9010.83.2.234.

Chang, H.-T., Hsu, H.-M., Liou, J.-W., \& Tsai, C.-T. (2013). Psychological contracts and innovative behavior: A moderated path analysis of work engagement and job resources. Journal of Applied Social Psychology, 43, 2120-2135. https://doi.org/10.1111/jasp. 12165.

Christian, M. S., Garza, A. S., \& Slaughter, J. E. (2011). Work engagement: A quantitative review and test of its relations with task and contextual performance. Personnel Psychology, 64(1), 89-136. https://doi.org/10.1111/j.1744-6570.2010.01203.x.

De Spiegelaere, S., Van Gyes, G., De Witte, H., Niesen, W., \& Van Hootegem, G. (2014). On the relation of job insecurity, job autonomy, innovative work behaviour and the mediating effect of work engagement. Creativity and Innovation Management, 23(3), 318330. https://doi.org/10.1111/caim.12079.

Demerouti, E. (2014). Design your own job through job crafting. European Psychologist, 19(4), 237-247. https://doi.org/10.1027/ 1016-9040/a000188.

Demerouti, E., \& Cropanzano, R. (2010). From thought to action: Employee work engagement and job performance. In A. B. Bakker \& M. P. Leiter (Eds.), Work engagement: A handbook of essential theory and research (pp. 147-163). New York: Psychology Press.

DiLiello, T. C., \& Houghton, J. D. (2006). Maximizing organizational leadership capacity for the future: Toward a model of self- 
leadership, innovation and creativity. Journal of Managerial Psychology, 21(4), 319-337.

Diedericks, E., \& Rothmann, S. (2014). Flourishing of information technology professionals: Effects on individual and organisational outcomes. South African Journal of Business Management, 45(1), 27 41. https://doi.org/10.4102/sajbm.v45i1.115.

Dubbelt, L., Demerouti, E., \& Rispens, S. (2019). The value of job crafting for work engagement, task performance, and career satisfaction: longitudinal and quasi-experimental evidence. European Journal of Work and Organizational Psychology, 28(3), 300-314.

Fischer, R., \& Poortinga, Y. H. (2018). Addressing methodological challenges in culture-comparative research. Journal of Cross-Cultural Psychology, 49(5), 691-712. https://doi.org/10.1177/ 0022022117738086

Gong, Y., Huang, J.-C., \& Farh, J.-L. (2009). Employee learning orientation, transformational leadership, and employee creativity: The mediating role of employee creative self- efficacy. The Academy of Management Journal, 52(4), 765-778. https://doi.org/10.1007/ s10869-014-9348-7.

Gupta, A. K., \& Kabe, D. G. (2011). A quadratic programming approach to a survey sampling cost minimization. Istanbul University Journal of the School of Business Administration, 40(1), 15-21.

Halbesleben, J. R. (2010). A meta-analysis of work engagement: Relationships with burnout, demands, resources, and consequences. Work engagement: A Handbook of Essential Theory and Research, $8(1), 102-117$.

Hanif, A., \& Bukhari, I. (2015). Relationship between innovative work behavior and job involvement among the employees of telecom sector. Pakistan Journal of Social and Clinical Psychology, 13(2), 23-29.

Harari, M. B., Reaves, A. C., \& Viswesvaran, C. (2016). Creative and innovative performance: A meta-analysis of relationships with task, citizenship, and counterproductive job performance dimensions. European Journal of Work and Organizational Psychology, 25(4), 495-511.

Janse van Rensburg, C., Rothmann, S., \& Diedericks, E. (2018). Job demands and resources: Flourishing and job performance in south African universities of technology settings. Journal of Psychology in Africa, 28(4), 291-297. https://doi.org/10.1080/14330237.2018. 1501881.

Janssen, O. (2000). Job demands, perceptions of effort-reward fariness and innovative work behaviour. Journal of Occupational and Organizational Psychology, 73, 287-302. https://doi.org/10.1348/ 096317900167038

Kahn, W. A. (1990). Psychological Conditions of Personal Engagement and Disengagement at Work. Academy of management journal, 33(4), 692-724.

Kataria, A., Garg, P., \& Rastogi, R. (2014). The role of work engagement in the pursuit of organisational effectiveness. International Journal of Indian Culture and Business Management, 9(1), 37-54. https:// doi.org/10.1504/IJICBM.2014.063962.

Kim, W., \& Park, J. (2017). Examining structural relationships between work engagement, organizational procedural justice, knowledge sharing, and innovative work behavior for sustainable organizations. Sustainability (Switzerland), 9, 1-16. https://doi.org/10.3390/ su11041050.

Kim, H., Park, N. K., \& Lee, J. (2014). How does the second-order learning process moderate the relationship between innovation inputs and outputs of large Korean firms? Asia Pacific Journal of Management, 31(1), 69-103.

Koopmans, L. (2014). Measuring individual work performance. Zutphen: CPI Koninklijke Wöhrmann. https://doi.org/10.3233/ WOR-131659.

Koopmans, L., Bernaards, C. M., Hildebrandt, V. H., Schaufeli, W. B., Vet, D., Henrica, C. W., \& Van der Beek, A. J. (2011). Conceptual frameworks of individual work performance a systematic review.
Journal of Occupational and Environmental Medicine, 53(8), 856-866. https://doi.org/10.1097/JOM.0b013e318226a763.

Lehner, F. (2018). ICT skills and competencies for SMEs: Results from a structured literature analysis on the individual level. In The Impact of Digitalization in the Workplace (pp. 55-69): Springer.

Lloyd, C., \& Payne, J. (2016). Skills in the age of over-qualification: Comparing service sector work in Europe. Oxford: Oxford University Press.

Luftman, J., \& Zadeh, H. S. (2011). Key information technology and management issues 2010-11: An international study. Journal of Information Technology, 26(3), 193-204. https://doi.org/10.1057/ jit.2011.3.

Luiijf, E., \& Klaver, M. (2015). Governing critical ICT: Elements that require attention. European Journal of Risk Regulation, 6(2), 263270.

Luiijf, E., \& Klaver, M. (2019). Resilience approach to critical information infrastructures. In Critical Infrastructure Security and Resilience (pp. 3-16). Cham: Springer.

Maleh, Y., Sahid, A., \& Belaissaoui, M. (2019). Strategic IT Governance and Performance Frameworks in Large Organizations, Hersey, PA, USA: IGI Global.

Mauno, S., Kinnunen, U., \& Ruokolainen, M. (2007). Job demands and resources as antecedents of work engagement: A longitudinal study. Journal of Vocational Behavior, 70(1), 149-171. https://doi.org/10. 1016/j.jvb.2006.09.002.

Mazetti, G., Schaufeli, W. B., \& Guglielmi, D. (2018). Are workaholism and work engagement in the eye of the beholder? A multi-rater perspective on different forms of working hard. European Journal of Psychological Assessment, 34, 30-40. https://doi.org/10.1027/ 1015-5759/a000318.

Milfont, T. L., \& Klein, R. A. (2018). Replication and reproducibility in cross-cultural psychology. Journal of Cross-Cultural Psychology, 49(5), 735-750. https://doi.org/10.1177/0022022117744892.

Muthén, L. K., \& Muthén, B. O. (2018). Mplus (version 8.1) [statistical software]. Los Angeles: Muthén \& Muthén.

Naidoo, R. (2016). A communicative-tension model of change-induced collective voluntary turnover in IT. The Journal of Strategic Information Systems, 25(4), 277-298.

Naqvi, S. M. M. R., \& Bashir, S. (2015). IT-expert retention through organizational commitment: A study of public sector information technology professionals in Pakistan. Applied Computing and Informatics, 11(1), 60-75.

Newton, S. K., Blanton, J. E., \& Will, R. (2008). Innovative work and citizenship behaviors from information technology professionals: Effects of their psychological contract. Information Resources Management Journal, 21(4), 27-48. https://doi.org/10.4018/irmj. 2008100102

Podsakoff, P. M., MacKenzie, S. B., Lee, J. Y., \& Podsakoff, N. P. (2003). Common method biases in behavioral research: A critical review of the literature and recommended remedies. Journal of Applied Psychology, 88(5), 879-903. https://doi.org/10.1037/0021-9010. 88.5.879.

Preacher, K. J., Zyphur, M. J., \& Zhang, Z. (2010). A general multilevel SEM framework for asessing multilevel mediation. Psychological Methods, 15(3), 209-233. https://doi.org/10.1037/a0020141.

Prescott, J., \& Bogg, J. (2011). Career attitudes of men and women working in the computer games industry. Eludamos. Journal for Computer Game Culture, 5(1), 7-28.

Ramamoorthy, N., Flood, P. C., Slattery, T., \& Sardessai, R. (2005) Determinants of innovative work behaviour: Development and test of an integrated model. Creativity and Innovation Management, 14(2), 142-150.

Rich, B. L., Lepine, J. A., \& Crawford, E. R. (2010). Job engagement: Antecedents and effects on job performance. The Academy of Management Journal, 53(3), 617-635. https://doi.org/10.5465/ amj.2010.51468988. 
Saks, A. M., \& Gruman, J. A. (2014). What do we really know about employee engagement? Human Resource Development Quarterly, 25(2), 155-182. https://doi.org/10.1002/hrdq.21187.

Salanova, M., \& Schaufeli, W. B. (2008). A cross-national study of work engagement as a mediator between job resources and proactive behaviour. The International Journal of Human Resource Management, 19(1), 116-131.

Schaufeli, W. B., \& Bakker, A. B. (2003). UWES - Work Engagement Scale. Test Manual. https://doi.org/10.1177/0013164405282471.

Schaufeli, W. B., Salanova, M., González-Romá, V., \& Bakker, A. B. (2002). The measurement of engagement and burnout: A two sample confirmatory factor analytic approach. Journal of Happiness Studies: An Interdisciplinary Forum on Subjective Well-Being, 3(1), 71-92. https://doi.org/10.1023/A:1015630930326.

Scholarios, D., Van der Heijden, B. I., Van der Schoot, E., Bozionelos, N., Epitropaki, O., Jedrzejowicz, P., et al. (2008). Employability and the psychological contract in European ICT sector SMEs. The International Journal of Human Resource Management, 19(6), $1035-1055$.

Shanker, R., Bhanugopan, R., Van der Heijden, B. I. J. M., \& Farrell, M. (2017). Organizational climate for innovation and organizational performance: The mediating effect of innovative work behavior. Journal of Vocational Behavior, 100, 67-77. https://doi.org/10. 1016/j.jvb.2017.02.004.

Shuck, B. (2011). Integrative literature review: Four emerging perspectives of employee engagement: An integrative literature review. Human Resource Development Review, 10(3), 304-328. https:// doi.org/10.1177/1534484311410840.

Shuck, B. (2019). Does my engagement matter? In The Oxford Handbook of Meaningful Work (p. 288). Oxford: Oxford University Press.

Smith, J. R., \& Haslam, S. A. (Eds.). (2017). Social psychology: Revisiting the classic studies. Upper Saddle River: Pearson Education Group.

Sonnentag, S. (2003). Recovery, work engagement, and proactive behavior: A new look at the interface between nonwork and work. Journal of Applied Psychology, 88(3), 518-528. https://doi.org/10.1037/ 0021-9010.88.3.518.
Sonnentag, S., Binnewies, C., \& Mojza, E. J. (2010). Staying well and engaged when demands are high: The role of psychological detachment. Journal of Applied Psychology, 95(5), 965.

Spector, P. E. (2019). Do not cross me: Optimizing the use of crosssectional designs. Journal of Business and Psychology, 34(2), $125-137$

Syrek, C. J., Apostel, E., \& Antoni, C. H. (2013). Stress in highly demanding it jobs: Transformational leadership moderates the impact of time pressure on exhaustion and work-life balance. Journal of Occupational Health Psychology, 18(3), 252-261. https://doi.org/ 10.1037/a0033085.

Tehseen, S., Ramayah, T., \& Sajilan, S. (2017). Testing and controlling for common method variance: A review of available methods. Journal of Management Sciences, 4(2), 142-168.

Thunnissen, M., Schippers, J., \& Boselie, P. (2018). Macro talent management in the Netherlands: A critical analysis of growing and retaining talent in the Netherlands. In Macro Talent Management (pp. 190-205). Abingdon: Routledge.

Tims, M., \& Bakker, A. B. (2010). Job crafting: Towards a new model of individual job redesign. SA Journal of Industrial Psychology, 36(2), $1-9$.

Van Der Wiel, H. (2001). Does ICT boost Dutch productivity growth? (No. 16). CPB Netherlands Bureau for Economic Policy Analysis.

Wang, J., \& Wang, X. (2012). Structural equation modeling: Applications using Mplus. Hoboken: Wiley.

West, M. A., \& Farr, J. L. (1989). Innovation at work: Psychological perspectives. Social Behaviour, 4(1), 15-30.

Yuan, F., \& Woodman, R. W. (2010). Innovative behavior in the workplace: The role of performance and image outcome expectations. Academy of Management Journal, 53(2), 323-342. https://doi.org/ 10.5465/amj.2010.49388995.

Publisher's note Springer Nature remains neutral with regard to jurisdictional claims in published maps and institutional affiliations. 